\title{
Fabrication of PMMA/ZnO nanocomposite: Effect of high nanoparticles loading on the optical and thermal
}

\section{properties}

\author{
Salim Hammani ${ }^{\mathrm{a}^{*}}$, Ahmed Barhoum ${ }^{\mathrm{b}, \mathrm{c}^{*}}$, Mikhael Bechlany ${ }^{\mathrm{d}}$ \\ a Laboratoire d'Analyse Fonctionnel et de Procédé Chimique Université Saad Dahlab-Blida1, \\ Route de Soumaa, 09000 Blida, Algérie. \\ ${ }^{\mathrm{b}}$ Department of Materials and Chemistry, Vrije Universiteit Brussel, B-1050 Brussels, \\ Belgium \\ ${ }^{\mathrm{c}}$ Chemistry Department, Faculty of Science, Helwan University, Helwan, Cairo 11795, Egypt \\ d Institut Européen des Membranes, UMR 5635 ENSCM UM CNRS, Université Montpellier, \\ Place Eugène Bataillon, 34095 Montpellier, France \\ Corresponding authors: hammani71@yahoo.fr, ahmed.abdelrasoul@vub.ac.be, \\ ahmed.barhoum@science.helwan.edu.eg
}

\begin{abstract}
$\mathrm{ZnO}$ nanoparticles (NPs) with a particle size less than $50 \mathrm{~nm}$, were prepared using thesolvothermal method from zinc acetate $\left(\mathrm{Zn}\left(\mathrm{CH}_{3} \mathrm{COO}\right)_{2} .2 \mathrm{H}_{2} \mathrm{O}\right)$ and hydrogen peroxide $\left(\mathrm{H}_{2} \mathrm{O}_{2}\right)$ in presence of organic solvent (methanol or ethanol). PMMA/ZnO nanocomposite films were prepared by blending $\mathrm{ZnO}$ NPs with polymethylmethacrylate (PMMA) using solution mixing at concentration range $0-40 \mathrm{wt} \%$. The results show that the methanol was more efficient in the synthesis of ZnO NPs than ethanol. The optical bandgap of PMMA/ZnO films has been decreased from 4.4 to $3.7 \mathrm{eV}$ by increasing the $\mathrm{ZnO}$ NPs content from $0 \mathrm{wt} \%$ (neat PMMA) to $40 \mathrm{wt} \%$. The thermal stability glass temperature (Tg), UV-shielding efficiency (reduced
\end{abstract}


transmission) were enhanced by about $60 \mathrm{~K}, 20 \mathrm{~K}, 40 \%$ with increasing ZnO NPs loading from 0 to $40 \mathrm{wt} \%$, respectively. The combination of the thermal and optical enhanced properties gives potential applications in different domains i.e.optics, photonics, and electronics.

Keywords: Zinc oxide, solvothermal method, polymethylmethacrylate nanocomposite, high nanoparticles loading, optical and thermal properties.

\section{Introduction}

Polymer nanocomposites are an attractive class of materials providing novel performance, due to their remarkable properties by using a low to high nanofiller loading [1-2]. Adding inorganic nanoparticle (NPs) to polymers can introduce specific functionalities (luminescence, catalytic activity, magnetism, etc.) and/or improve the electrical conductivity, mechanical properties, thermal stability, and flame retardancy [3].Keeping the inorganic NPs homogeneously dispersed (isolated) is crucial for creating smart composite materials that retain the flexibility and fluidity of the polymer matrix (host) while incorporating a high fraction of inorganic NPs with their associated properties. However, aggregation of NPs deteriorates the polymer properties (i.e. optical, thermal and mechanical properties) [4-5] except for a few cases where a limited NPs aggregation exhibited some improvements [6].

Generally, there are four general approaches for dispersing NPs in polymers [7-9]: (i) High shear mixing of the polymer and NPs by extrusion for polymer melts; (ii) High shear mixing or ultrasonic irradiation for dispersion of NPs in the polymer solution and then evaporation of the solvent. However, dispersion of NPs in polymer matrix cannot be achieved only by mechanical mixing without any chemical bonding and optimized interaction between the matrix and NPs; (iii) in-situ polymerization in the presence of NPs [10]; (iv) modification of the surface by chemical treatment and the grafting of functional polymeric molecules to the active sites (e.g. -OH) existing on the particle surface; (v) both the formation of the 
nanoparticles and the polymerization in-situ $[11,12]$. It has been proved from the literature that homogenous distribution of inorganic NPs in the polymer matrix at a high content of $>10 \mathrm{wt} \%$ NPs is not possible because of the immiscibility and high surface energy of NPs.

Transparent polymer nanocomposites which exhibit various optical properties such as tailored emission/absorption properties, low/high refractive index, or strong nonlinearities optical properties attracts great interest because of the potential optoelectronic applications [13]. These polymer nanocomposites are typically obtained by the incorporation of metal oxide NPs into a transparent polymer matrix (e.g. PMMA). While the polymeric component contributes to good processability, transparency, and flexibility, the NPs provide the desired thermal, electrical and optical properties [14,15]. The technological and economic advantages of polymers have been amply demonstrated in the fields of automotive, chemical sensors and electronics $[16,17]$. Scientists are particularly interested in polymer-based nanocomposites to combine the properties of NPs and polymers [18-20].

PMMA as a transparent polymeric material offers excellent transparency in the visible and near-infrared range, as well as dielectric constants generally lower than those of the inorganic materials [21], which allows fast response times, shorter than in the case of crystals inorganic compounds. It is often used as an alternative to glass. PMMA has a transmission of more light and much lighter than silica glass (1.19 versus $2.20 \mathrm{~g} \mathrm{~cm}^{-3}$ in density, respectively). However, neat PMMA exhibits some disadvantages, for example, poor thermal stability, which restricts it from high-temperature applications. PMMA transmits UV light thus manufacturers usually apply UV coatings on PMMA to overcome this deficiency [22]. A variety of inorganic nanofillers were mixed with an organic matrix, including PMMA/nanoclay [23-24], PMMA/SiO 2 [25,26] and PMMA/MWCNTs [27]. These types of systems were showed improved optical properties allow applications in optoelectronics and optical domains [28,29]. PMMA/ZnO nanocomposites were extensively studied in the literature [22,30-34]. It may be 
due mainly to the wide number of advantages presented in different domains (optics, electronics and the simple methods of preparation). ZnO NPs is a well-known multifunctional inorganic filler that has outstanding properties such high refractive index, large exciton binding energy (nearly $60 \mathrm{meV}$ ) [35-36], high thermal conductivity and antibacterial and UV-protection properties [22]. ZnO NPs usually exhibit a near-band-edge (NBE) UV line accompanied by a strong visible luminescence. However, the most crucial aspects of high luminescence efficiencies from ZnO NPs are the surface texture and an efficient surface passivation. Recent studies show that capping of $\mathrm{ZnO}$ NPs with polymers can effectively passivate the surface and reduce the surface-related visible emission [37-38].

Many studies were focused on the thermal degradation behavior of the PMMA/ZnO nanocomposites, because of its properties and applications in chromatography, medicine, and optics [34]. The blending of ZnO NPs with PMMA is believed to improve the optical properties of the polymer, however, refractive index mismatch may cause strong optical scattering which diminishes the transparency of the composites. The mismatch is tolerable when the particle size (2r) is much smaller than the wavelength $(\lambda)$ of the incident light $(2 r<\lambda / 10)$ [9]. $\mathrm{ZnO}$ presents other properties as n-type semiconductor with a wide bandgap (3.36-3.39eV) [39], and presents appealing features such as biocompatibility, nontoxicity and inexpensiveness [40,41]. Thus it has been extensively used in the fabrication of electronic and optical devices [30]. $\mathrm{ZnO}$ NPs are environmentally friendly [42] and nontoxic to the cells comparing with many other inorganic NPs such as CdTe, CdS and CdSe [43].

The present study focuses on the effect of blending ZnO NPs with PMMA. Firstly, the ZnO NPs was synthesized using the solvothermal method. The obtained ZnO NPs were blended with PMMA by solution mixing to prepare PMMA/ZnO nanocomposite films. The dispersion of $\mathrm{ZnO} \mathrm{NPs}$ and morphology, thermal stability and UV-shielding capability of the nanocomposite films were investigated by scanning electron microscopy (SEM), thermal 
gravimetrical analysis (TGA), differential scanning calorimetry (DSC), and UV-vis spectroscopy.

\section{Experimental Section}

\subsection{Synthesis of $\mathrm{ZnO}$ nanoparticles}

Approximately $8.4 \mathrm{~g}$ of zinc acetate dihydrate $\left(\mathrm{Zn}\left(\mathrm{CH}_{3} \mathrm{COO}\right)_{2} .2 \mathrm{H}_{2} \mathrm{O}\right.$, Panreac, $\left.99 \%\right)$ was added to $266 \mathrm{ml}$ of doubly distilled water with continuous stirring for $25 \mathrm{~min}$ at $50^{\circ} \mathrm{C}$. Subsequently, $400 \mathrm{ml}$ of methanol $\left(\mathrm{CH}_{3} \mathrm{OH}\right.$, Sigma-Aldrich, $\left.99.7 \%\right)$ or ethanol $\left(\mathrm{C}_{2} \mathrm{H}_{5} \mathrm{OH}\right.$, Sigma-Aldrich, 96\%) was added gradually with continuous stirring for $3 \mathrm{~h}$. Then $4 \mathrm{ml}$ of hydrogen peroxide $\left(\mathrm{H}_{2} \mathrm{O}_{2}\right.$, Panreac, 47\%) was added dropwise and with stirring until a clear solution is obtained. This solution was incubated for $24 \mathrm{~h}$ at ambient temperature and pressure and then dried at $80^{\circ} \mathrm{C}$ for $6 \mathrm{~h}$ to obtain a white powder. The white powder was washed three times with doubly distilled water. After washing, the $\mathrm{ZnO}$ powder was dried at $80^{\circ} \mathrm{C}$ in a drying oven and then calcined at $600{ }^{\circ} \mathrm{C}$ for $1 \mathrm{~h}$.

\subsection{Preparation of nanocomposite films}

The granulate PMMA (Vedril Spa-Resina Metallica) manufactured (Motedison as a supplier) was used, with $\mathrm{T}_{\mathrm{g}}=105^{\circ} \mathrm{C}$. In order to prepare the nanocomposite film, the PMMA granulate $(1 \mathrm{~g})$ was dissolved in $50 \mathrm{ml}$ of THF solvent when the mixture becomes white and viscous. Different amounts of the $\mathrm{ZnO}$ powder ( $\mathrm{ZnO}$ NPs) were added. The solution was stirred at $60^{\circ} \mathrm{C}$ for $90 \mathrm{~min}$. When the solution becomes white, the gel was spread on the glass plate to obtain a nanocomposite film. The thin film was placed in an oven heated to $70{ }^{\circ} \mathrm{C}$ for $11 \mathrm{~min}$ to remove the trace solvent. The thickness of PMMA and PMMA/ZnO films was measured by a micrometer (Vernier Digital Palmer) at different positions (4 to 6 points), the mean film thickness kept at about $(20 \pm 1 \mu \mathrm{m})$. The composition of the nanocomposites film was summarized in Table 1. 
Table 1: Nanocomposites prepared with different contents of $\mathrm{ZnO}$ in THF solvent.

\begin{tabular}{|c|c|c|}
\hline Samples & PMMA (g) & $\mathrm{ZnO}(\mathrm{g})$ \\
\hline Neat PMMA & 1.00 & 0.00 \\
\hline PMMA/ZnO 1\% & 0.99 & 0.01 \\
\hline PMMA/ZnO 2\% & 0.98 & 0.02 \\
\hline PMMA/ZnO 5\% & 0.95 & 0.05 \\
\hline PMMA/ZnO 10\% & 0.90 & 0.10 \\
\hline PMMA/ZnO 40\% & 0.60 & 0.40 \\
\hline
\end{tabular}

\subsection{Characterization of $\mathrm{ZnO} \mathrm{NPs}$ and PMMA/ZnO nanocomposite}

Phase identification of the prepared $\mathrm{ZnO}$ NPs was performed using an X-ray diffractometer (PANalyticalXpert-PRO diffractometer equipped with an accelerator detector using Ni-filtered $\mathrm{Cu}$-radiation) with $\mathrm{Cu} \mathrm{K} \alpha$ radiation $(\lambda=0.15406 \mathrm{~nm})$ at $40 \mathrm{kV}$ and $20 \mathrm{~mA}$. The scanning step size was $0.0167113^{\circ}$. The crystalline size of $\mathrm{ZnO}$ particles was determined from the XRD data using the Debye-Scherrer equation [44].

$$
d=\frac{K \lambda}{\beta \cos \theta}
$$

Where $(d)$ is the crystallite size, $(K)$ is a dimensionless shape factor, with a value close to unity. The shape factor has a typical value of about 0.9 , but varies with the actual shape of crystallite, $(\beta)$ is the full-width at half maximum (FWHM) of the most intense diffraction peak, $(\lambda)$ is the wavelength of $\mathrm{Cu}$ target, and $(\theta)$ is the Bragg angle.

The morphology and the chemical composition of the PMMA/ZnO films were examined by field-emission scanning electron microscopy (FESEM) using Quanta 650 model with an acceleration voltage of $10 \mathrm{kV}$ and low vacuum. 
A Varian-Cary system 500 UV-VIS-NIR spectrophotometer was used to determine the optical properties (UV-vis absorption) of the nanocomposites films at ambient temperature. The optical bandgap energy of different nanocomposites PMMA/ZnO was calculated using the flowing formula [45].

$$
(\alpha h v)=A\left(h v-E_{g}\right)^{1 / 2}
$$

Where $\alpha, h, v, E_{g}$ and $A$ are absorption coefficient, Planck constant, light frequency, band gap energy and $A$ constant, respectively. The bandgap energy $(E g)$ values of different nanocomposites films were calculated from the intercept of $(\alpha h v)^{2}$ versus $(h v)$ curves by extraplotting tangent to them.

Thermogravimetric analysis (TA Instruments, TGA Q500, USA) was used to detect the thermal degradation of neat PMMA and PMMA/ZnO nanocomposites with different amounts of $\mathrm{ZnO}$. The samples were heated to $60^{\circ} \mathrm{C}$ and held at this temperature for $30 \mathrm{~min}$ and heated at $10 \mathrm{~K} \cdot \mathrm{min}^{-1}$ from 60 to $700{ }^{\circ} \mathrm{C}$ under air atmosphere. The residue (at $600{ }^{\circ} \mathrm{C}$ ) on the TGA curves presents the estimated amount of $\mathrm{ZnO}$ in the prepared nanocomposites. Thermal characterization was performed using a TA Instruments Q20 DSC to evaluate the glass transition of the nanocomposites. Samples were heated from 20 to $200^{\circ} \mathrm{C}$ at a heating/cooling rate of $10 \mathrm{~K} \cdot \mathrm{min}^{-1}$ under $\mathrm{N}_{2}$ atmosphere. The glass transition temperature was determined using universal analysis software provided by TA.

\section{Results and discussion}

\subsection{Influence of solvent nature on ZnO NPs preparation}

The solvothermal method is one of the most efficient and easiest methods to produce ZnONPs. In a solvothermal synthesis of ZnO NPs, a solvent (methanol or ethanol) acts as a reaction medium. Using different types of organic solvents with different structures, single crystalline ZnO NPs of different morphologies can be obtained [46]. In this study, two types of 
solvent were used in the synthesis of the ZnO NPs in order to evaluate the effect of different solvents. ZnO NPs with different yields were obtained in methanol and ethanol solvent. The mass yield of $\mathrm{ZnO}$ NPs obtained in presence of methanol is much higher than that obtained in ethanol. This means that the conversion of the hydroxides into $\mathrm{ZnO}$ was promoted in presence of methanol $\left(\mathrm{CH}_{3}-\mathrm{OH}\right)$ more than ethanol $\left(\mathrm{CH}_{3}-\mathrm{CH}_{2}-\mathrm{OH}\right)$. There are several factors may contribute the hydrolysis of $\mathrm{Zn}^{2+}$ and formation of $\mathrm{ZnO}$ NPs: length of the alkyl chain, steric hindrance, and polarity of the solvent molecules. Based on this result the methanol solvent was suggested in all preparations.

\subsection{Polymorph and crystal structure of $\mathrm{ZnO}$ NPs}

The X-ray diffraction pattern of the obtained $\mathrm{ZnO}$ nanoparticles is shown in Fig. 1. All sharp diffraction peaks at $2 \theta=31.7(100), 34.4(002)$ and $36.2(101)$ in the two graphs prepared in ethanol and methanol solvents. The synthesis of $\mathrm{ZnO}$ generally gives wurtzite [47] or zincite hexagonal crystal structure $[13,48]$. The prepared $\mathrm{ZnO}$ were indexed to the zincite hexagonal crystal structures. The peak positions were in an agreement with those observed by Yadav et al. [48]. The X-ray diffraction results and the average crystallite size value calculated by the Scherer equation confirm that the $\mathrm{ZnO}$ crystallites elaborated either in methanol or in ethanol gave the crystalline size of about $44 \mathrm{~nm}$ 


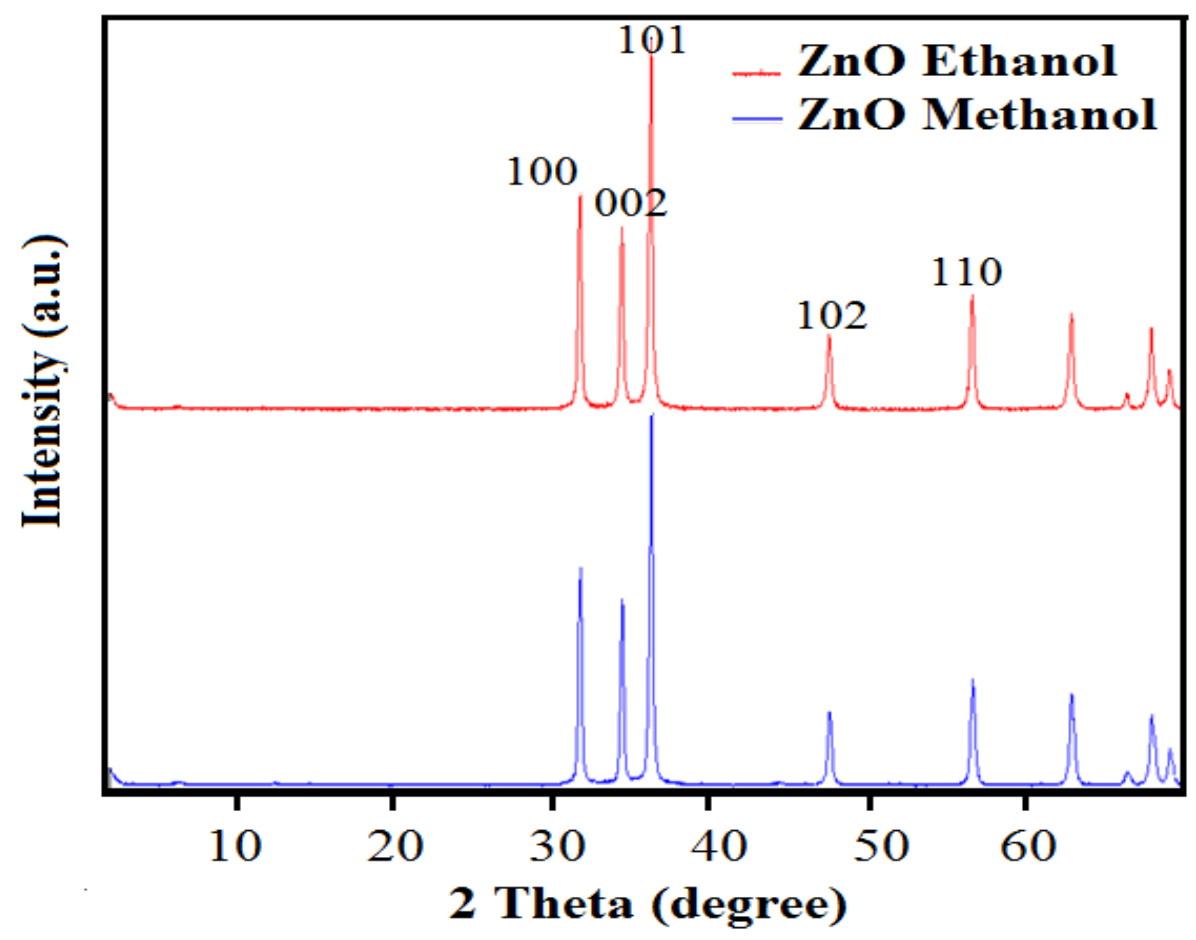

Fig. 1 XRD pattern of synthesis of ZnO NPs prepared in presence of ethanol and methanol.

\section{3-3. Morphological development of PMMA/ZnO nanocomposites}

The evolution of ZnO NPs dispersion is important since the well-dispersed NPs can lead to a significant improvement in PMMA properties. Homogeneous dispersion of $\mathrm{ZnO}$ NPs is desired to avoid creation of crack-initiatives in the PMMA film. In order to visualize the effect of high $\mathrm{ZnO}$ NPs loaded (0-40wt\%) on the distribution and the dispersion of the nanofiller in the polymer PMMA matrix, SEM was used. Fig. 2 shows SEM images of the PMMA/ZnO films prepared with 5 and $10 \mathrm{wt} \% \mathrm{ZnO}$ NPs. The $5 \mathrm{wt} \%$ PMMA/ZnO film shows a good dispersion of the $\mathrm{ZnO}$ NPs without agglomeration. The average diameter of the dispersed phase (Fig. 2) was about $50 \mathrm{~nm}$. The bright phase presents the ZnO NPs with nonuniform distribution when the amount of $\mathrm{ZnO}$ NPs increases up to $10 \mathrm{wt} \%$. The agglomeration observed at $10 \mathrm{wt} \%$ PMMA/ZnO film presents a poor dispersion of ZnO NPs in the polymer matrix (PMMA).The average size of the agglomeration was estimated equal to $3 \mu \mathrm{m}$, the average size of the aggravate increases from $0.3 \mu \mathrm{m}$ to $3 \mu \mathrm{m}$ with increasing the $\mathrm{ZnO}$ NPs loading from $5 \mathrm{wt} \%$ to $10 \mathrm{wt} \%$. 
This phenomenon was the most challenging in the dispersion of the nanoparticles in the polymeric matrix, because the NPs tend to agglomerate due to high surface energy $[45,49]$. The size of the aggregation has a considerable influence on thermal and optical properties of the nanocomposites [13]. A very narrow size distribution is strictly required because scattering intensity is proportional to $\left(r^{3}\right)$ ( $r$ : particle radius). The presence of even a small percentage of particles or aggregates, therefore, larger than $100 \mathrm{~nm}$ leads to strong scattering in the visible and therefore causes haze or even turbidity [13].
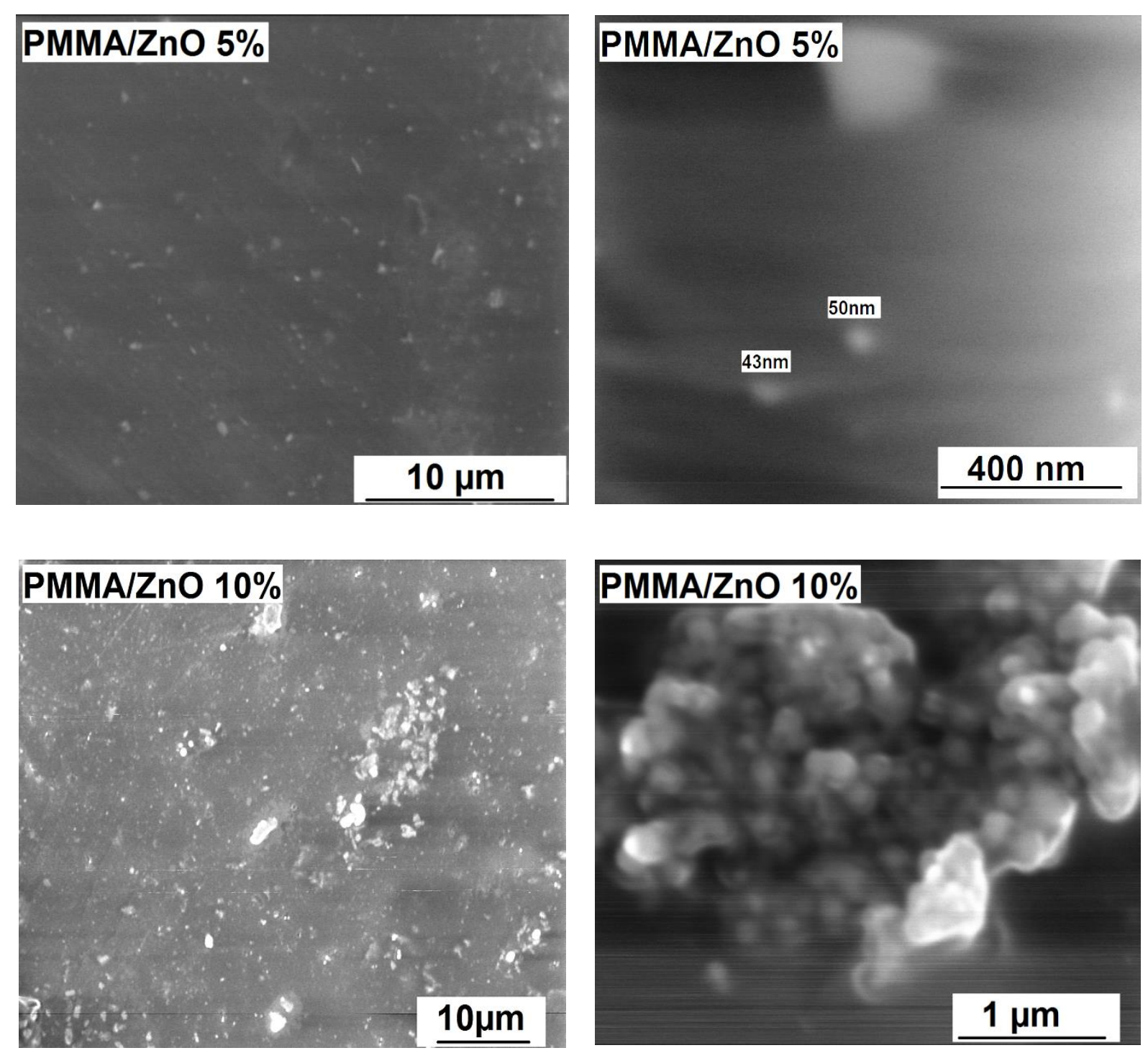

Fig. 2: Morphological development of PMMA/ZnO nanocomposites with 5 and $10 \mathrm{wt} \%$ of $\mathrm{ZnO}$ in PMMA. 
Fig. 3 presents the energy dispersive X-ray (EDX) analysis of 10wt\% PMMA/ZnO nanocomposites. The EDX analysis shows the existence of three characteristic elements of the polymer and nanoparticle (PMMA/ZnO) which are represented by the $\mathrm{C}, \mathrm{Zn}$ and $\mathrm{O}$ peaks. The different elements exist in the materials that we are used during the preparation of the nanocomposites, indicating the successful formation of nanocomposite with high purity. The $\mathrm{C}$ peak is attributed to the PMMA while those for $\mathrm{Zn}$ are attributed to $\mathrm{ZnO}$ NPs and the O peak is a contribution between PMMA and $\mathrm{ZnO}$.

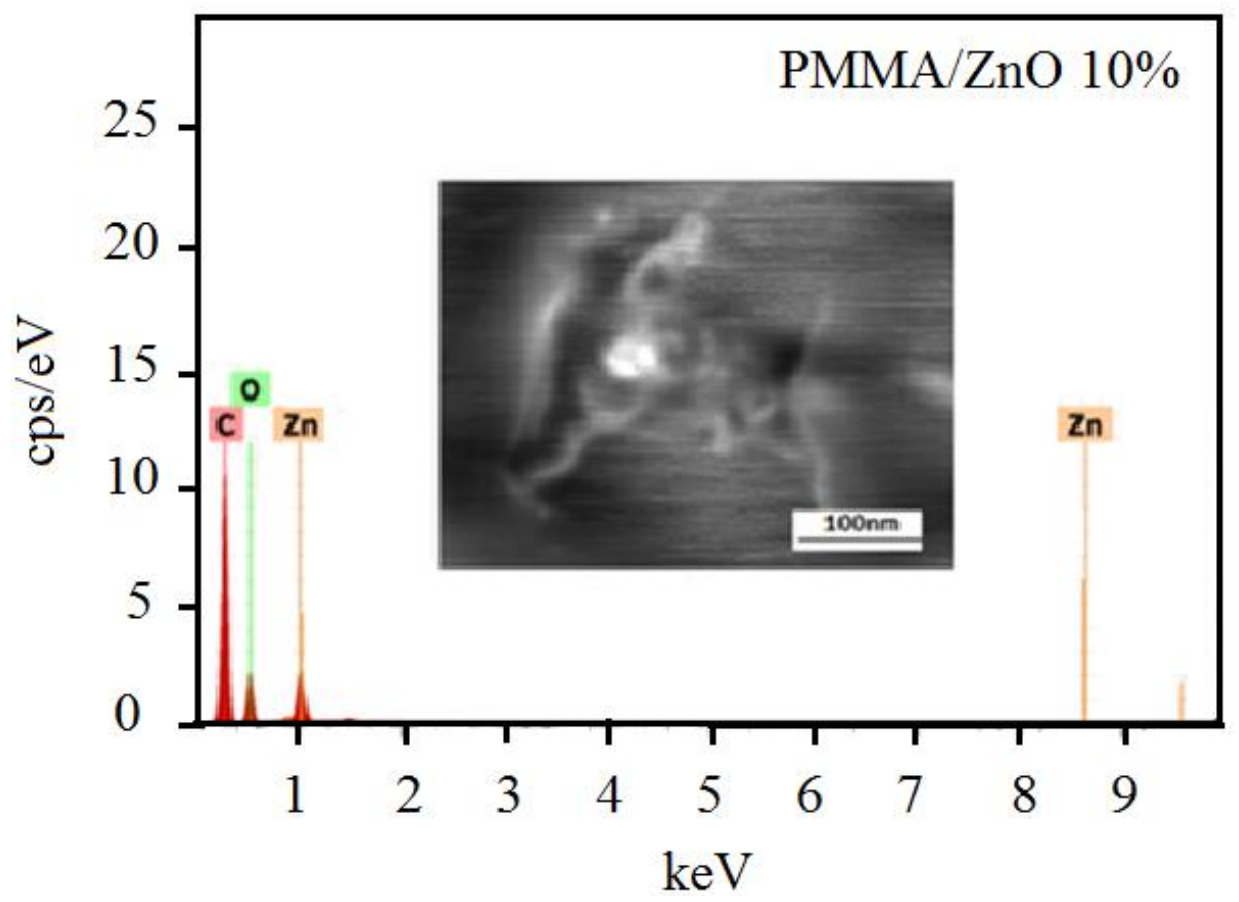

Fig. 3 SEM-EDX analysis of the nanocomposite film PMMA/ZnO 10 wt\%.

\subsection{Tuning the optical properties of PMMA/ZnO film}

Fig. 4 shows the UV-vis transmission and absorption spectra of PMMA and PMMA/ZnO nanocomposites as a function of wavelength. The PMMA/ZnO films loaded with $2 \mathrm{wt} \% \mathrm{ZnO}$ NPs has a high transparency in the visible range compared to the films loaded with higher $\mathrm{ZnO}$ contents $10-40 \mathrm{wt} \%$. The increase of $\mathrm{ZnO}$ NPs content in the PMMA matrix from 2 to $10 \mathrm{wt} \%$ reduces the transmission of light in the visible range up to 33-37\%. This drop-in transparency is mainly attributed to the scattering of the light with relatively short wavelengths 
by the larger aggregates formed in the PMMA/ZnO films as $\mathrm{ZnO}$ NPs concentration increases from 2-10 wt $\%$. The transmission of PMMA/ZnO films decreases further with increasing $\mathrm{ZnO}$ NPs concentration from 10-40wt\%. Aggregation of ZnO NPs at high loading from 10-40 wt $\%$ results in a high UV-reflectivity but also leads to a lower factor of transmission for the visible spectrum. Demir et al. [13] reported that blending of ZnO NPs with PMMA is believed to improve the optical properties of the PMMA/ZnO film. However, the difference between refractive index of $\mathrm{ZnO}$ and that of PMMA (refractive index mismatch) results in a strong optical scattering which diminishes the transparency of the nanocomposites [13]. Fig. 4b shows that the absorption maximum of the PMMA/ZnO films is shifted to higher wavelengths compared to the neat PMMA. The neat PMMA and 2wt\% PMMA/ZnO films do not absorb UV light down to $300 \mathrm{~nm}$ in wavelength, while the PMMA/ZnO films containing ZnO NPs (10$40 \mathrm{wt} \%$ ) absorb UV-light at around $380 \mathrm{~nm}$ ( $\lambda$ onset), down to $250 \mathrm{~nm}$. The peaks of absorption of PMMA/ZnO films shown at $\sim 380 \mathrm{~nm}(3.29 \mathrm{eV})$ corresponding to the exciton state in the pure ZnO NPs [50]. The 10wt\% PMMA/ZnO films containing show good UV-shielding efficiency, and the more ZnO NPs in PMMA, the more UV light is absorbed. 

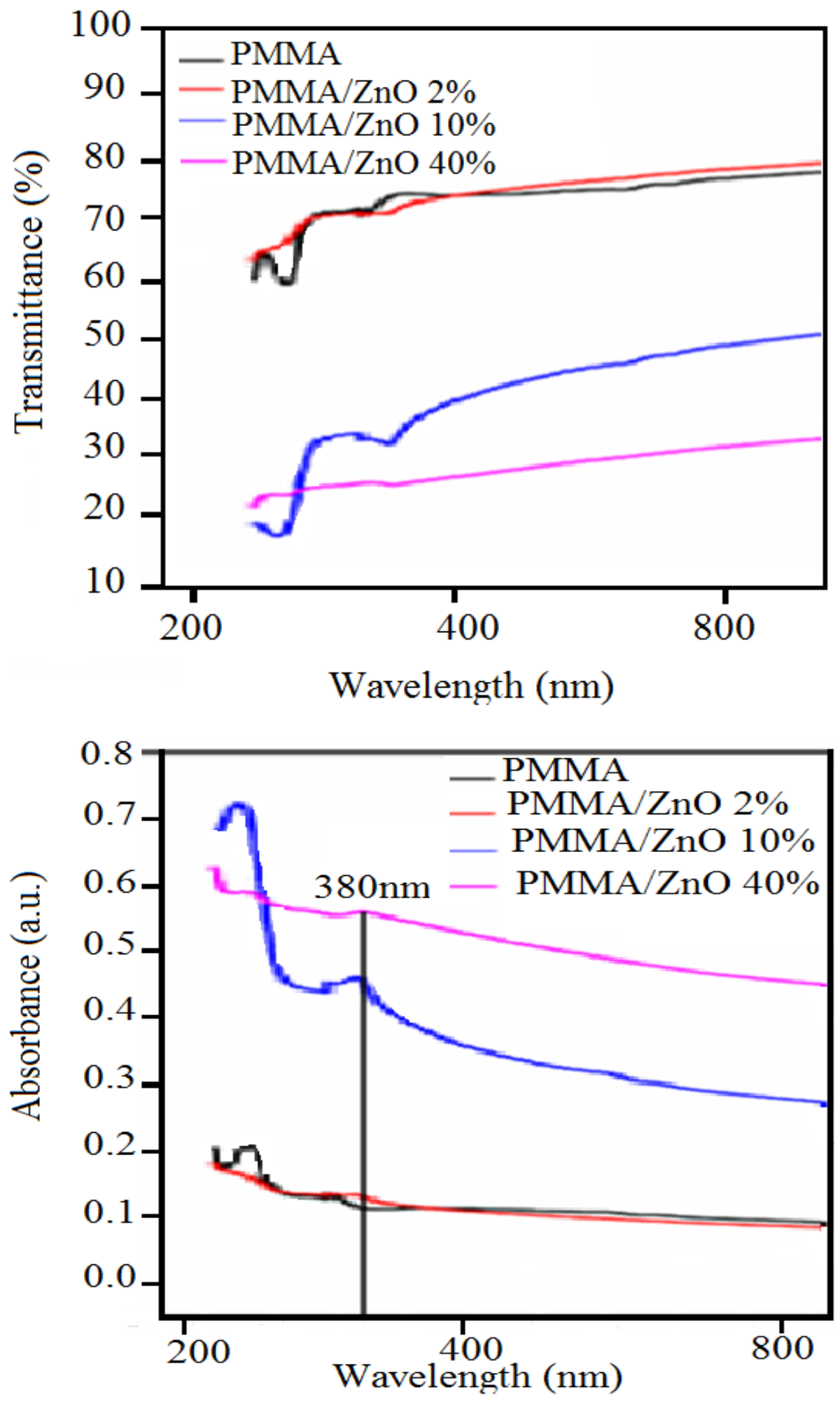

Fig. 4 UV-vis transmission and absorbance spectra of the nanocomposite films with different $\mathrm{ZnO}$ NPs concentrations (0, 2, 10 and $40 \mathrm{wt} \%$ of $\mathrm{ZnO}$ NPs). 
The measurement of optical bandgap energy was performed using Tau's plot, plotting $\left((\alpha h v)^{2}\right)$ as a function of $(h v), \alpha$ is absorption coefficient and $v$ is the frequency of light used. The optical bandgap was determined from the extrapolation of the linear portion of the graph to the photon energy axis (Fig. 5a). The optical bandgap of PMMA/ZnO films has been decreased from $4.4 \pm 0.2$ to $3.7 \pm 0.2 \mathrm{eV}$ by increasing the $\mathrm{ZnO}$ NPs content from $0 \mathrm{wt} \%$ (neat PMMA) to $40 \mathrm{wt} \%$.
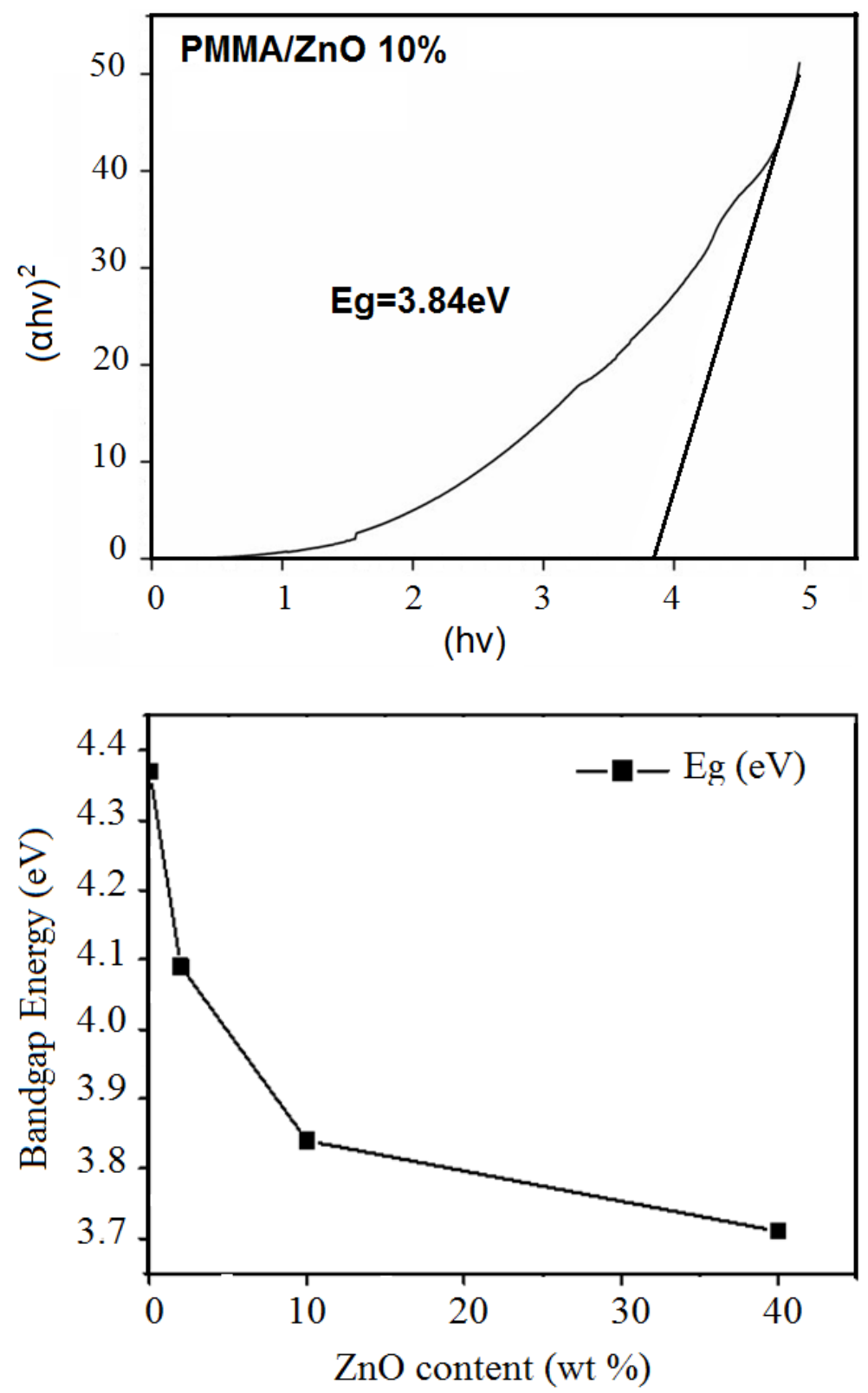
Fig. 5. (a) Variation of $(\alpha h v)^{2}$ as a function of (hv) of PMMA/ZnO 10wt\% nanocomposites, (b) Variation of the optical bandgap of the PMMA/ZnO nanocomposite films as a function of $\mathrm{ZnO}$ NPs content.

Figure $5 b$ shows the variation of the optical bandgap energy of nanocomposites films versus the $\mathrm{ZnO}$ NPs loading. The optical bandgap is inversely proportional to the $\mathrm{ZnO}$ NPs loading in PMMA/ZnO nanocomposites. The bandgap values decrease from $4.37 \mathrm{eV}$ for pure PMMA to $3.71 \mathrm{eV}$ when the amount of $\mathrm{ZnO}$ NPs reached $40 \mathrm{wt} \%$. Therefore, this decrease in the bandgap energy is mainly due to the charges are given by the ZnO NPs and the increase of the $\mathrm{ZnO}$ size particle due to the agglomeration phenomenon. The experimental results of the bandgap energy are in good agreement with predicted theoretical results [51,52]. These results also are constituents with by Lee et al. [52] who reported that the increase of the particle size (aggregate size) of the NPs increases significantly the bandgap energy of the nanocomposite. Similar results were shown by Thakur et al. [53] in $\mathrm{PVC}^{\mathrm{PE} / \mathrm{TiO}}{ }_{2}$, the optical bandgap decreases with the increase of the $\mathrm{TiO}_{2} \mathrm{NPs}$ content in the blend polymer.

\section{3-6. Glass transition temperature}

The thermograms of neat PMMA and PMMA/ZnO nanocomposites are shown in Fig. 6. All the PMMA/ZnO nanocomposite films show glass transition temperature ( $\mathrm{Tg}$ ) higher than that of the neat PMMA. Tg of the neat PMMA was about $90.5^{\circ} \mathrm{C}$ (Table 2). This value of $\mathrm{Tg}$ is much lower of about $10 \mathrm{~K}$ in comparison to the value gives by the supplier $\left(102^{\circ} \mathrm{C}\right)$. This may be due to the dissolution of the PMMA in the solvent that diminishes the molecular weight distribution (MWD) since the glass transition temperature ( $\mathrm{Tg}$ ) is directly related to the polymer chain mobility [54]. 
Table 2 shows that all nanocomposites present a higher Tg compared to that of neat PMMA. Enhancement of Tg of the PMMA matrix with the addition of inorganic NPs was discussed in the literature. For example, Nikolaidis et al. [55] show that the increase of $\mathrm{Tg}$ of nanocomposites (PMMA/Cloisite) was due to the production of materials with higher MWD compared to the neat PMMA. This can be attributed to the increase in the length of the macroradicals before they find one another and terminate. The dispersion of $\mathrm{ZnO}$ NPs in the PMMA matrix will hinder the movement of macromolecules and increase the $\mathrm{Tg}$ of the sample. At a low loading of $\mathrm{ZnO}$ in the nanocomposites, the $\mathrm{Tg}$ increase of 5 to $10 \mathrm{~K}$ (Table 2). At the high amount of $\mathrm{ZnO}$ (40 wt\%), a spectacular enhancement of $\mathrm{Tg}$ of about $22 \mathrm{~K}$ is observed. Khan et al. [56] show that the addition of $14 \mathrm{~nm} \mathrm{ZnO} \mathrm{NPs} \mathrm{enhances} \mathrm{the} \mathrm{Tg}$ of the nanocomposites by about $26 \mathrm{~K}$ at $1 \mathrm{wt} \%$ of $\mathrm{ZnO}$. The difference between our results and Khan et al. [56] is probably due to the aggregate size of ZnO NPs in the PMMA matrix.

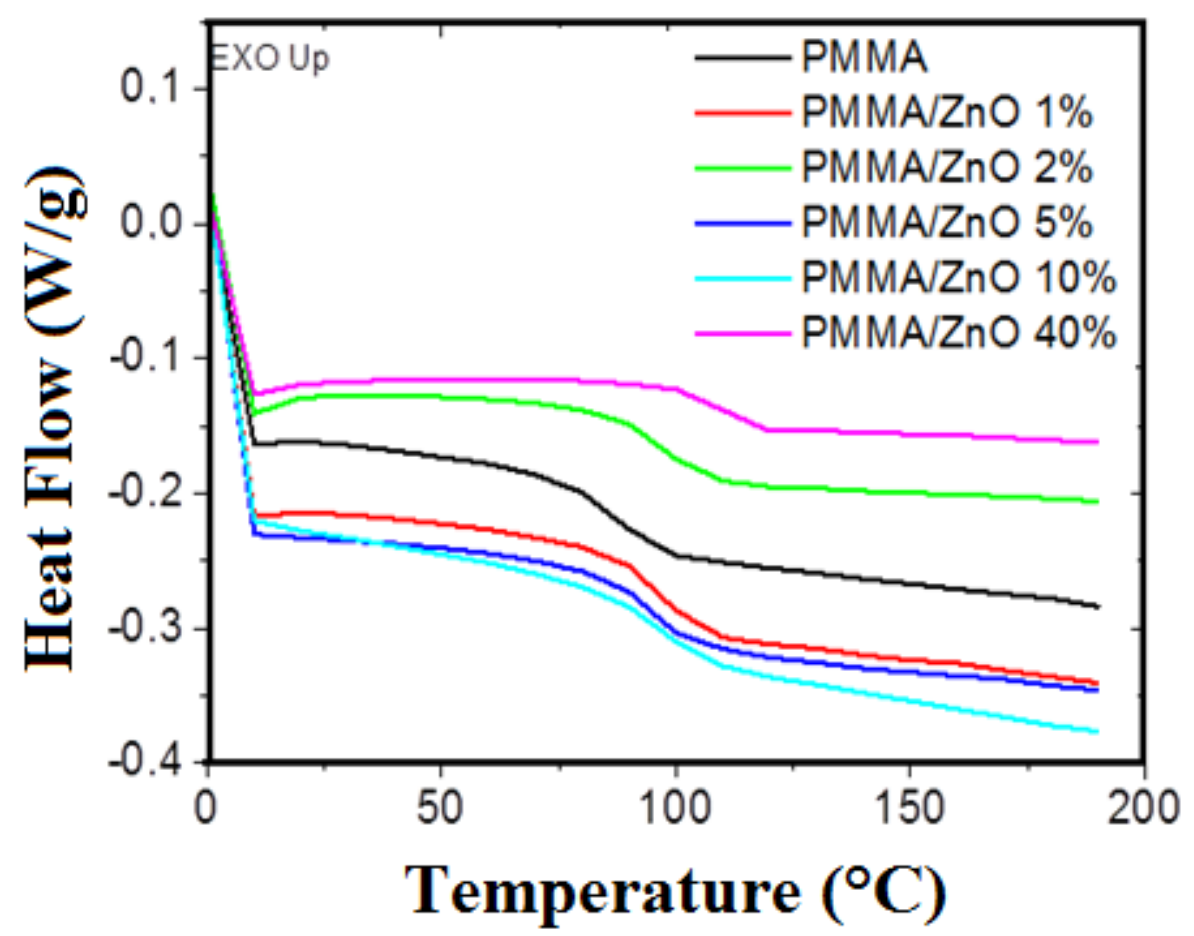

Fig. 6: DSC curves of the PMMA/ZnO nanocomposite films at different $\mathrm{ZnO}$ NPs content. 


\subsection{Thermal stability}

Figure 7 shows TG and DTG curves of neat PMMA and PMMA/ZnO nanocomposites with different contents of ZnO NPs. The neat PMMA (Fig. 8b) was presented by three main steps of degradation. The last step was completely separated from the other. The first step was between $\mathrm{T}=102^{\circ} \mathrm{C}$ and $230^{\circ} \mathrm{C}$, mass loss of about $7 \mathrm{wt} \%$ was attributed to the evaporation of residual solvent [56-58] and probably a depolymerization step initiated at weak head-to-head linkages arising from chain termination by combination and vinylidene chain ends that result from disproportionation $[59,60]$. The interval of the second step was situated between $230^{\circ} \mathrm{C}$ and $404^{\circ} \mathrm{C}$. This DTG peak refers to degradation initiated by random scission of the polymer backbone of neat PMMA, about 92 wt\% of the total weight of the PMMA sample. The peak presents an overlapping due probably to the complexity of the decomposition of PMMA. This degradation was attributed to the radical transfer to unsaturated chain ends and random scission [61].

It can be seen that TG and DTG curves of PMMA/ZnO nanocomposites were different from neat PMMA. All PMMA/ZnO nanocomposites show that the first peak $\left(\mathrm{T}_{\text {peak }}\right)$ was delayed of about $50 \mathrm{~K}$ compared to the neat PMMA with increasing the ZnO NPs content upto $40 \mathrm{wt} \%$ (Figure 7a). This may be due to the facile liberation of the residual solvent due to the enhancement of the thermal conductivity in the samples with the presence of the ZnO NPs.

The main peak of DTG of neat PMMA (second degradation) was disturbed by different little peaks. The addition of $1-5 \mathrm{wt} \%$ of $\mathrm{ZnO}$ to PMMA eliminated this anomaly and the main degradation was presented by two succeeds peaks. The same shape of degradation was preserved in PMMA/ZnO with 2 and 5wt\% nanocomposites. The DTG curve of the $10 \mathrm{wt} \%$ and 40wt\% PMMA/ZnO nanocomposites show only one sharp peak at $415 \pm 5$ and $443 \pm 5^{\circ} \mathrm{C}$. The disappearance of the third step (see Table 2) occurs gradually with increasing ZnO NPs but it is very significant even at $10-40 \% \mathrm{ZnO}$ NPs. This result was in good agreement with Demir et 
al. [13] results, who prepared PMMA/ZnO composite through in-situ polymerization of (MMA) monomers in the presence of modified ZnO NPs. The thermal stability properties were increased with increasing the $\mathrm{ZnO}$ NPs loading.

The addition of ZnO NPs in PMMA enhances the stability of the nanocomposites (Fig. 7b). A spectacular enhancement was observed at higher $\mathrm{ZnO}$ content when the main degradation peak increases of about $60 \mathrm{~K}$ compared to the main peak of PMMA. The enhancement of the thermal stability of PMMA prepared with increasing ZnO NPs can be attributed to the formation of char which hinders the out-diffusion of the volatile decomposition products. The $\mathrm{ZnO}$ NPs remaining at the surface hinder the diffusion of oxygen into the bulk PMMA film thus slowing down the last step of the degradation process [3]. The analysis of the residue results by TG curves (Table 2) shows that the amounts of $\mathrm{ZnO}$ NPs revealed by TG curves was superior to that estimated by our preparation in a low amount of $\mathrm{ZnO}$ NPs (Table 2).

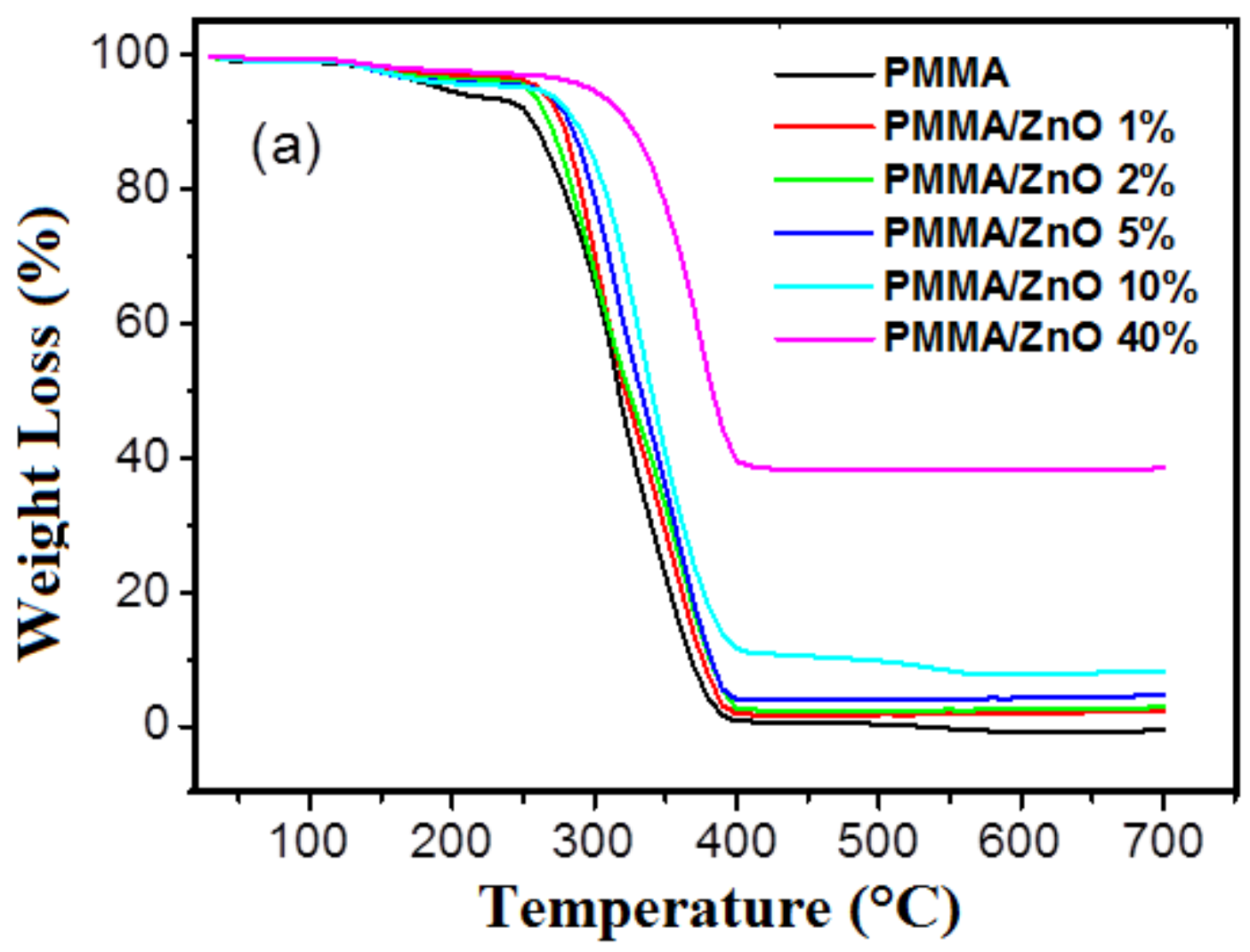




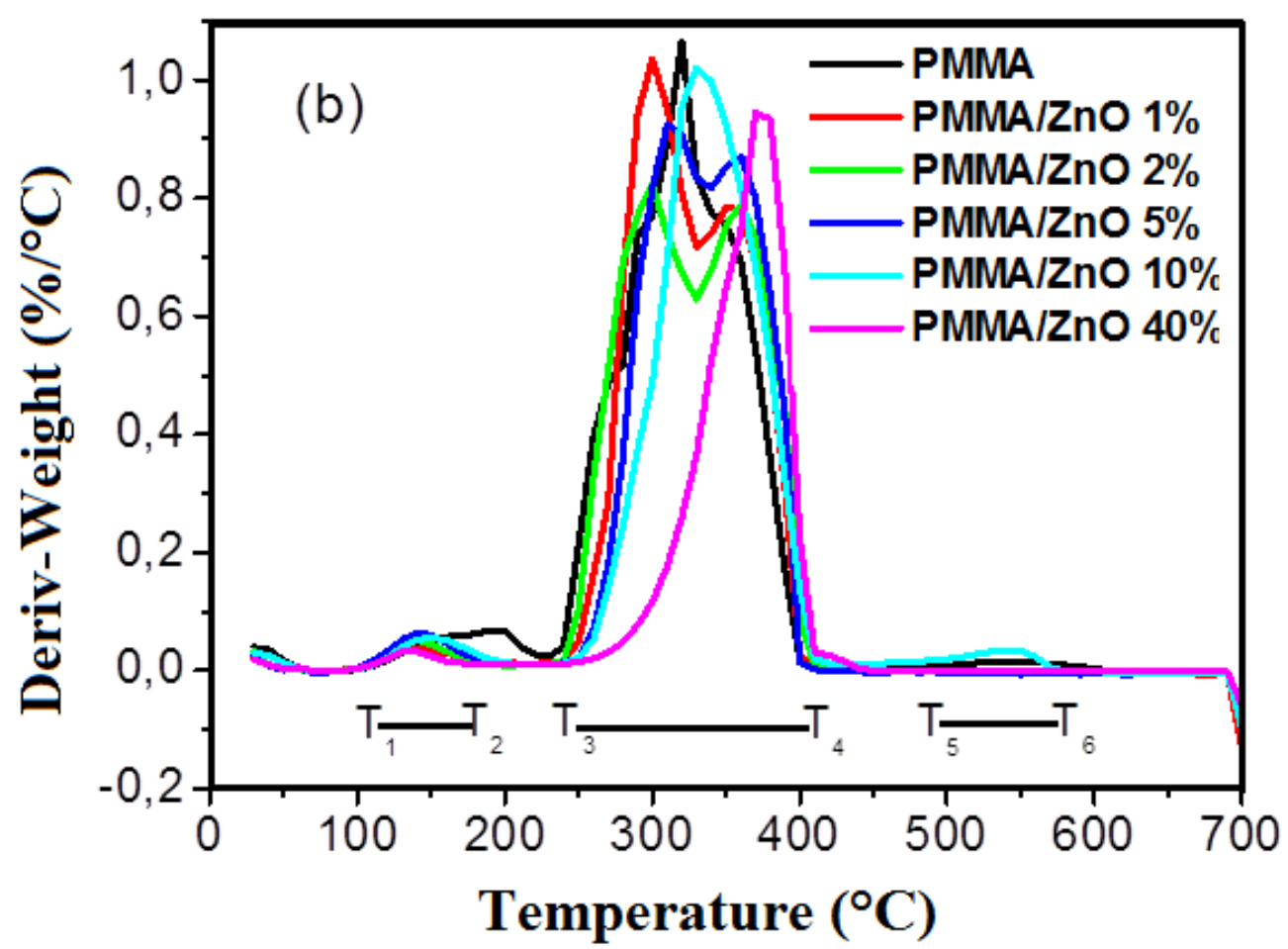

Fig. 8: Thermograms of the neat PMMA and nanocomposites PMMA/ZnO with different ZnO NPs content: (a) TGA curves; and (b) derivative DTG curves

Table 2: TGA and DSC data of the neat PMMA and PMMA/ZnO nanocomposite films

\begin{tabular}{|c|c|c|c|c|c|c|c|c|c|c|c|}
\hline \multirow{3}{*}{ Sample } & \multirow[t]{2}{*}{$\mathrm{Tg}$} & \multicolumn{9}{|c|}{ Thermal Stability } & \multirow{2}{*}{ Residue } \\
\hline & & \multicolumn{3}{|c|}{ Step 1} & \multicolumn{3}{|c|}{ Step 2} & \multicolumn{3}{|c|}{ Step 3} & \\
\hline & ${ }^{\circ} \mathrm{C}$ & $\begin{array}{c}\mathrm{T}_{1} \\
\left({ }^{\circ} \mathrm{C}\right)\end{array}$ & $\begin{array}{c}\mathrm{T}_{2} \\
\left({ }^{\circ} \mathrm{C}\right)\end{array}$ & $\begin{array}{l}\text { Wt } \\
\text { loss } \\
(\%)\end{array}$ & $\begin{array}{c}\mathrm{T}_{3} \\
\left({ }^{\circ} \mathrm{C}\right)\end{array}$ & $\begin{array}{c}\mathrm{T}_{4} \\
\left({ }^{\circ} \mathrm{C}\right)\end{array}$ & $\begin{array}{l}\mathrm{Wt} \\
\text { loss } \\
(\%)\end{array}$ & $\begin{array}{c}\mathrm{T}_{5} \\
\left({ }^{\circ} \mathrm{C}\right)\end{array}$ & $\begin{array}{c}\mathrm{T}_{6} \\
\left({ }^{\circ} \mathrm{C}\right)\end{array}$ & $\begin{array}{l}\mathrm{Wt} \\
\text { loss } \\
(\%)\end{array}$ & $\begin{array}{l}\mathrm{ZnO} \\
\mathrm{wt} \%\end{array}$ \\
\hline Neat PMMA & 90.5 & 132 & 230 & 6.5 & 230 & 403 & 92.5 & 499 & 637 & 0.8 & 0.0 \\
\hline PMMA/ZnO(1\%) & 97.8 & 115 & 212 & 5.0 & 230 & 331 & 52 & 331 & 402 & 50.3 & 1.7 \\
\hline PMMA/ZnO(2\%) & 100.2 & 104 & 220 & 4.7 & 220 & 326 & 47.5 & 326 & 409 & 44.2 & 2.3 \\
\hline PMMA/ZnO(5\%) & 95.6 & 117 & 222 & 4.3 & 241 & 337 & 49.2 & 337 & 405 & 45.2 & 4.3 \\
\hline PMMA/ZnO(10\%) & 96.0 & 118 & 230 & 4.5 & 239 & 415 & 89.6 & 470 & 577 & 2.5 & 7.9 \\
\hline
\end{tabular}




\begin{tabular}{|l|l|l|l|l|l|l|l|l|l|l|l|}
\hline PMMA/ZnO(40\%) & 112.6 & 107 & 214 & 2.5 & 241 & 443 & 59.2 & - & - & - & 38.3 \\
\hline
\end{tabular}

T1, T3, and T5 represent the start points of weight loss steps 1, 2, 3 whereT2, T4, and T6 represent the endpoints of the weight loss steps $1,2,3$, respectively.

\section{Conclusion}

Homogeneous dispersion of inorganic NPs, especially at high NPs content $>10 \mathrm{wt} \%$, in a polymeric matrix is highly challenging. In this study, the effect ZnO NPs loading at PMMA films (0-40 wt $\%)$ on the morphological, thermal and optical properties of PMMA was investigated. The optical properties of the PMMA/ZnO nanocomposites show that all films are transparent at low $\mathrm{ZnO}$ loading. The increase of $\mathrm{ZnO}$ NPs content from 0 to $40 \mathrm{wt} \%$ in PMMA matrix decreases the optical bandgap from 4.4 to $3.7 \mathrm{eV}$, respectively. The increase of $\mathrm{ZnO} \mathrm{NP}$ content in the nanocomposites films increases the glass transition temperature $(+20 \mathrm{~K})$ and enhances the thermal stability $(+60 \mathrm{~K})$ of the PMMA/ZnO films along with UV-shielding capability. However, the pure PMMA and PMMA films loaded with 1-2 wt\% ZnO NPs has a high transparency in the visible range compared to the films loaded with higher $\mathrm{ZnO}$ contents $10-40 \mathrm{wt} \%$. The combination of the enhanced properties of PMMA/ZnO films opens a large way to these nanocomposites in different applications (solar energy and optical domains).

\section{ACKNOWLEDGMENT}

A.B. would like to thank FWO - ResearchFoundationFlanders (grant no V450315N) and the Strategic Initiative Materials in Flanders (SBO- project no. 130529 - INSITU) for financial support. S. H. would like to thank FUNDAPL and Chemical Department of Blida University to support this research works.

\section{No conflicts of interest exist}




\section{References}

[1] Sanaz A,SiyamakS,Nor Azowa I,Fatehi A (2012) Enhancement of Mechanical and Thermal Properties of Polycaprolactone/Chitosan Blend by Calcium Carbonate Nanoparticles,Int J Mol Sci 13(4):4508-4522.

[2] Khrenov V, Klapper M, Koch M, Mullen K (2005) Surface Functionalized ZnO Particles Designed for the Use in Transparent Nanocomposites, Macromol Chem Phys 206:95101.

[3] Barhoum A, Van Lokeren L,.Rahier H, Dufresne A, VanAssche G (2015) Roles of in situ surface modification in controlling the growth and crystallization of $\mathrm{CaCO} 3$ nanoparticles, and their dispersion in polymeric materials,J Mater Sci50:7908-7918.

[4] Kongsinlark A,,Rempel G, Prasassarakich P (2012) Synthesis of monodispersed polyisoprene-silica nanoparticles via differential microemulsion polymerization and mechanical properties of polyisoprene nanocomposite, Chem Eng J 193-194:215-226.

[5] Tucureanu V, Matei A, Mihalache L, Danila M, Popescu M, Bita B (2015) Synthesis and characterization of YAG:Ce,Gd and YAG:Ce,Gd/PMMA nanocomposites for optoelectronic applications, J Mat Sci 50(4): 1883-1890.

[6] Oberdisse J (2006) Aggregation of colloidal nanoparticles in polymer matrices, Soft Matter, 2:29-36.

[7] Peng XM, Chen YW, Li F, Zhou WH, Hu YH (2009) Preparation and optical properties of ZnO@PPEGMA, Appl Surf Sci. 255:7158-7163.

[8] Chen XL, Zhou ZW,Lv WC, Huang T, Hu SC (2009) Preparation of core-shell structured T-ZnOw/polyaniline composites via graft polymerization, Mater Chem and Phys 115(1):258-262.

[9] Sanchez C, Julian B, Belleville P and Popall M (2005) Applications of hybrid organicinorganic nanocomposites, J Mater Chem 15:3559-3592. 
[10] Chen L, Wang C, Li Q, Yang S, Hou L, Chen S (2009) In situ synthesis of transparent fluorescent $\mathrm{ZnS}$-polymer nanocomposite hybrids through catalytic chain transfer polymerization technique, J Mat Sci 44(13) 3413-3419.

[11] Morselli D, Messori M, Bondioli F (2011) Poly(methyl methacrylate)$\mathrm{TiO}_{2}$ nanocomposite obtained by non-hydrolytic sol-gel synthesis J Mat Sci 466609.

[12] Weickmann H, Delto R, Thomann R, Brenn R, Döll W, Mülhaupt R, (2007) PMMA nanocomposites and gradient materials prepared by means of polysilsesquioxane (POSS) self-assembly, J Mat Sci 42(1) 87-92.

[13] Demir MM, Koynov K, Akbey U, Bubeck C, Park I, Lieberwirth I, Wegner G (2007) Optical Properties of Composites of PMMA and Surface-Modified Zincite Nanoparticles, Macromol 40: 1089-1100.

[14] DaiPrè M, Martucci A, J. Martin D, Lavina S, Di Noto V (2015) Structural features, properties, and relaxations of PMMA-ZnO nanocomposite, J Mat Sci 50(5) 2218-2228.

[15] Johnson LP, Matisons JG (2009) Investigation of the thermal and structural properties of single-molecule magnet/polymer nanocomposite films, J Mat Sci 44(11) 2805-2813.

[16] Gao F (2004) Clay/polymer composites: the story, Materialstoday 7(11): 50-55.

[17] Bogue R, (2011) Nanocomposites: a review of technology and applications, Assem. Autom 31(2): 106-112.

[18] Salafsky JS, Lubberhuizen WH, Schropp REI (1998) Photoinduced charge separation and recombination in a conjugated polymer-semiconductor nanocrystal composite, Chem Phys Letts 209: 297-303.

[19] Cheng J, Wang S, Li XY, Yan Y, Yang S, Yang CL Wang JN, Ge WK (2001) Fast interfacial charge separation in chemically hybridized CdS-PVK nanocomposites studied by photoluminescence and photoconductivity measurements, Chem Phys Letts 333: 375380. 
[20] Sun L, Fu X, Wang M, Liu C, Liao C, Yan C (2000) Synthesis of CdS nanocrystal within copolymer, J Lumin 87- 89: 538-541.

[21] Zettl M, Mayer O,,Klampaftis E and Richards BS (2016) Host Polymer Investigation for Luminescent Solar Concentrators, Energy Technol 10.1002/ente.201600498.

[22] Sun DZ,,Miyatake N, Sue HJ (2007) Transparent PMMA/ZnO nanocomposite films based on colloidal ZnO quantum dots, Nanotechnology 18: 215606/1-6.

[23] Brostow W, Dutta M, Ricardode Souza T,Rusek P, Marcos de Medeiros A, Ito EN (2010) Nanocomposites of poly(methyl methacrylate) (PMMA) and montmorillonite (MMT) Brazilian clay: A tribological study. eXPRESS.Polym. Lett 4(9): 570-575.

[24] Zheng J, Su Q, Wang C, Cheng G, Zhu R, Shi J, Yao K (2011) Synthesis and biological evaluation of PMMA/MMT nanocomposite as denture base material, J Mater Sci: Mater M 22 (4): 1063-1071.

[25] Yang F, Nelson GL (2004) PMMA/silica nanocomposite studies: Synthesis and properties, JApplPolym. Sci 91(6): 3844, 3850.

[26] Fu HP, Hong RY, ZhangYJ,LiHZ,XuB,Zheng Y and Wei DG (2009) Preparation and properties investigation of PMMA/silica composites derived from silicic acid, Polym Adv Technol 20: 84-91.

[27] Li Z, Chen S, Nambiar S,SunY,Zhang M, Zheng W, Yeow JT (2016) PMMA/MWCNT nanocomposite for proton radiation shielding applications, Nanotechnology 27(23): 234001.

[28] Kodama RH, Nash AE, Spada FE, and Berkowitz AE (1994): NATO Advanced Study Institute on Nanophase Materials, HadjipanayisGC and Siegel RW (eds.), Kluwer Academic Publishers : pp. 101. 
[29] Sreeja R, John J, Aneesh PM, Jayaraj MK (2010) Linear and nonlinear optical properties of luminescent $\mathrm{ZnO}$ nanoparticles embedded in PMMA matrix, Opt Commun 283(14): 2908-2913.

[30] Matsuyama K, Mishima K, Kato T, Irie K, Mishima K (2012) Transparent polymeric hybrid film of $\mathrm{ZnO}$ nanoparticle quantum dots and PMMA with high luminescence and tunable emission color, J. Colloid Interface Sci 367: 171-177.

[31] Shim JW, Kim JW, Han SH, ChangIh-S, Kim HK, Kang HH, Lee OS, Suh KD (2002) Zinc oxide/polymethylmethacrylate composite microspheres by in situ suspension polymerization and their morphological study, Colloid. Surf A 207: 105-111.

[32] Balen R, Vidotto da Costa W,,De Lara Andrade J, et al (2016) Structure, thermal, optical properties and cytotoxicity of PMMA/ZnO fibers and films: Potential application in tissue engineering, Appl Surf Sci 385: 257-267.

[33] Eita M, Wågberg L and Muhammed M (2012) Spin-Assisted Multilayers of Poly(methyl methacrylate) and Zinc Oxide Quantum Dots for Ultraviolet-Blocking Applications, ACS Appl Mater Interfaces 4: 2920-2925.

[34] Sato M, Kawata A, Morito S, Sato Y, Yamaguchi I (2008) Preparation and properties of polymer/zinc oxide nanocomposites using functionalized zinc oxide quantum dots, Eur Polym J 44: 3430-3438.

[35] Barhoum A,,Van Assche G, Rahier H, Fleisch M, Bals S, Delplancked M-P, Leroux F,,Bahnemann D (2017) Sol-gel hot injection synthesis of $\mathrm{ZnO}$ nanoparticles into a porous silica matrix and reaction mechanism, Mater \& Design 119: 270-276.

[36] Barhoum A, Melcher J, Van Assche G, Rahier H, Bechelany M, Fleisch M, Bahnemann D (2017)Synthesis, growth mechanism, and photocatalytic activity of Zinc oxide nanostructures: porous microparticles versus nonporous nanoparticles. J Mater Sci 52: 2746-2762. 
[37] Yang CL, Wang JN, and Ge WK (2001) Enhanced ultraviolet emission and optical properties in polyvinyl pyrrolidone surface modified $\mathrm{ZnO}$ quantum dots, J Appl Phys 90(6): 4489.

[38] Tong YH, Liu YC, Lu S.X, Dong L, Chen SJ ,Xiao ZY (2004)The Optical Properties of ZnO Nanoparticles Capped with Polyvinyl Butyral, Sol-Gel,,SciTechnol 30: 157-161.

[39] Bechelanyl M, Amin A, Brioude A (2012) ZnO nanotubes by template-assisted sol-gel route, J Nanoparticle Res 14 (8): 980.

[40] Elias J, Utke I, Yoon S (2013) Electrochemical growth of ZnO nanowires on atomic layer deposition coated polystyrene sphere templates,Eectrochimica Acta 110 (SI): 387-392.

[41] Andre RS, Pavinatto A, Mercante LA, Paris EC, Mattoso LH, and Correa DS (2015) Improving the electrochemical properties of polyamide 6/polyaniline electrospun nanofibers by surface modification with $\mathrm{ZnO}$ nanoparticles, RSC Adv 5(90): 7387573881.

[42] Demir MM, Memesa M, Castignolles P, Wegner G, (2006) PMMA/Zinc Oxide Nanocomposites Prepared by In-Situ Bulk Polymerization, Macromol Rapid Commun 27: $763-770$.

[43] Hardman R (2006) A Toxicologic Review of Quantum Dots: Toxicity Depends on Physicochemical and Environmental Factors, Environ,Hlth.Persp 114(2): 165-172.

[44] Bindu P, Thomas S (2014) Estimation of Lattice Strain in ZnO Nanoparticles: X-ray Peak Profile Analysis, J Theor Appl Phys 8: 123-134.

[45] Kumar N, Mittal H, Reddy L, Nair P, Ngila JC and Parashar V (2015) Morphogenesis of $\mathrm{ZnO}$ nanostructures: role of acetate $\left(\mathrm{COOH}^{-}\right)$and nitrate $\left(\mathrm{NO}_{3}^{-}\right)$ligand donors from zinc salt precursors in synthesis and morphology dependent photocatalytic properties, RSC Adv 5: 38801-38809. 
[46] Khoza PB, Moloto MJ and Sikhwivhilu LM, (2012) The Effect of Solvents, Acetone,Water, and Ethanol, on the Morphological and Optical Properties of $\mathrm{ZnO}$ Nanoparticles Prepared by Microwave, J Nanotechnology 1-6.

[47] Ilangovan P, Sakvai MS, Kottur AB (2017) Synergistic Effect of Functionally Active Methacrylate Polymer and ZnO Nanoparticles on Optical and Dielectric Properties, Mater Chem Phys 193: 203-211.

[48] Yadav A, Prasad V, KatheA and Yadav D (2006) Functional Finishing in Cotton Fabrics Using Zinc Oxide Nanoparticles, Bull Mater Sci 29(6): 641-645.

[49] Kyprianidou-Leodidou T, Margraf P, Caseri W, Suter UW, Walther P (1997) Polymer sheets with a thin nanocomposite layer acting as a UV filter, Polym Adv Technol 8: 505512.

[50] Kulyk B, Kapustianyk V, Tsybulskyy V, Krupka O, Sahraoui B, (2010) Optical properties of ZnO/PMMA nanocomposite films, J Alloys Compd 502:24-27.

[51] Sharma AC (2006) Size-dependent energy band gap and dielectric constant within the generalized Penn model applied to a semiconductor nanocrystallite,„J Appl Phys. 100: 084301.

[52] Lee EJH, Ribeiro C, Giraldi TR, Longo E, Leite ER, Varela JA (2004) Photoluminescence in quantum-confined $\mathrm{SnO}_{2}$ nanocrystals: evidence of free exciton decay, Appl Phys Lett.84: 1745-1747.

[53] Thakur A, Thakur P, Yadav K, (2017) Morphological, Optical and Thermal Properties of $(\mathrm{TiO} 2) \mathrm{x}$ Embedded $(\mathrm{PVC} / \mathrm{PE}) 1-\mathrm{x}($ Where $\mathrm{x}=0.0,0.1,0.2,0.3,0.4$ and 0.5$)$ Blend Nanocomposites, Springer Proceed Phys 178: 89-100.

[54] Kim D, Jeon K, Lee Y, Seo J, Seo K, Han H, Khan S (2012) Preparation and characterization of UV-cured polyurethane acrylate/ZnO nanocomposite films based on surface modified $\mathrm{ZnO}$, Prog Org Coat 74: 435-442. 
[55] Nikolaidis A.K, Achilias DS, Karayannidis GP (2011) Synthesis and Characterization of PMMA/Organomodified Montmorillonite Nanocomposites Prepared by in Situ Bulk Polymerization, Ind Eng Chem Res 50 (2): 571-579.

[56] Khan M, Chen M, Wei C, Tao J, Huang N, Qi Z, Li L, (2014) Synthesis at the nanoscale of $\mathrm{ZnO}$ into poly(methyl methacrylate) and its characterization, Appl Phys A 117: 10851093.

[57] Zhang Y, Zhuang S, Xu X, Hu J (2013) Transparent and UV-shielding ZnO@PMMA nanocomposite films, Opt. Mater 36: 169-172.

[58] Raoufi D, Raoufi T (2009) The effect of heat treatment on the physical properties of solgel derived ZnO thin films, Appl Surf Sci255: 5812-5817.

[59] Kandare E, Deng H, Wang D,Hossenlopp JM (2006) Thermal Stability and Degradation Kinetics of Poly(methyl Methacrylate)/Layered Copper Hydroxy Methacrylate Composites, Polym Adv Techno 117( 4): 312-319

[60] Holland BJ, Hay JN (2002) The effect of polymerization conditions on the kinetics and mechanisms of thermal degradation of PMMA, Polym. Degrad. Stab 77: 435-439.

[61] Kashiwagi T, Inaba A, Brown JE, Hatada K, Kitayama T, Masuda E (1986) Effects of weak linkages on the thermal and oxidative degradation of poly(methy1 methacrylates), Macromol 19: 2160-2168. 